\title{
Chitosan/polyethylene glycol fumarate blend films for wound dressing application: in vitro biocompatibility and biodegradability assays
}

\author{
Azadehsadat Hashemi Doulabi ${ }^{1} \cdot$ Hamid Mirzadeh $^{1} \cdot$ Mohammad Imani $^{2} \cdot$ Shadab Bagheri-Khoulenjani $^{1}$
}

Received: 28 March 2018 / Accepted: 10 July 2018 / Published online: 18 July 2018

(c) The Author(s) 2018

\begin{abstract}
Blending is one of the effective approaches in preparing tailored materials with a wide range of properties. Thus, chitosanbased polymers have been fabricated and used as wound dressings since they possess better properties than those of the constituent materials. The objective of this work was to evaluate the biocompatibility and biodegradability of biodegradable blend films based on polyethylene glycol-co-fumarate (PEGF) and chitosan (Ch). The blend films of $\mathrm{Ch} / \mathrm{PEGF}$ were prepared by solution casting/solvent evaporation method. Degradation behavior of these blend films was evaluated in a simulated fluid at physiological pH supplemented with lysozyme at a concentration similar to that in human serum by weight loss of the films and changes in the $\mathrm{pH}$ of media. When the $\mathrm{pH}$ of incubation media was analyzed, with an increase of PEGF content in the blend films, the degradation rate increased accordingly. The $\mathrm{pH}$ of the media of samples was not significantly changed at any measured time point and all films kept their integrities during 28 days. The biocompatibility of the films and cell behavior on the surface of these films were investigated by in vitro tests. Biological assessment using mouse fibroblast cell line L929 on the blend films of Ch/PEGF indicated that films supported the attachment, spreading and proliferation of cells. Since the Ch/PEGF films are biocompatible with the tailored biodegradation rate, they might have a great prospective position in the application of wound dressings.
\end{abstract}

Keywords Chitosan $\cdot$ Blend $\cdot$ Biodegradation $\cdot$ Cell behaviour $\cdot$ Wound dressing

\section{Introduction}

The degradation rate of a wound dressing film has to match the rate of wound healing during the healing process (Cao and Wang 2009). Faster degradation is not desirable as the healing will remain unsupported and a slower degradation rate might cause an unwanted immune reaction or host response. Hence, a trade-off has to be achieved between structural integrity and the rate of degradation of the wound covering polymeric mass (Kean and Thanou 2010). Chitosan (Ch) is a biocompatible, biodegradable, non-toxic and antibacterial biopolymer that has been well known as being able to accelerate the healing process of wounds in humans (Mir

Hamid Mirzadeh

Mirzadeh@aut.ac.ir

1 Department of Polymer Engineering, Amirkabir University of Technology, P.O. Box 15875/4413, Tehran, Iran

2 Department of Novel Drug Delivery Systems, Iran Polymer and Petrochemical Institute, P.O. Box 14965/115, Tehran, Iran et al. 2018; Muzzarelli 2009). Blending is one of the effective approaches to prepare a material as tailored and with a wide range of properties (Ahmed and Ikram 2016; Muxika et al. 2017; Usman et al. 2016). Poly(ethylene glycol-cofumarate) (PEGF) block copolymer is a biocompatible, cytocompatible, biodegradable aliphatic unsaturated polyester with tunable mechanical properties (Hashemi Doulabi et al. 2013a). The Ch/PEGF blend films were prepared for obviating the inherent drawbacks of neat $\mathrm{Ch}$ and neat PEGF for wound dressing applications and simultaneously improving $\mathrm{Ch} / \mathrm{PEGF}$ biological properties (Hashemi Doulabi et al. 2013a, b). Chitosan degrades into oligosaccharides by the enzymatic action of lysozyme in vivo (Nordtveit et al. 1996) and PEGF undergoes non-enzymatic bulk hydrolysis of its ester linkage followed by fragmentation into oligomers (Hashemi Doulabi et al. 2008). Preparing a blend film of these two polymers in different blend ratios seems to tailor the surface properties such as surface roughness resulting in changes of cell adhesion. It was reported that $\mathrm{Ch}$ / PEGF blend films were potential candidates as wound dressings due to some of their properties such as antibacterial 
activity, permeability and fluid absorption (Hashemi Doulabi et al. 2013b, 2015). Motivated by our preliminary results (Hashemi Doulabi et al. 2013b), the main goal of this research was to investigate in vitro degradability, biocompatibility and cytocompatibility of $\mathrm{Ch} / \mathrm{PEGF}$ blend films as important requirements for a wound dressing material. Their biodegradation profile and in vitro cell behavior response confirmed their potential for medical applications. To the best of our knowledge, long-term in vitro degradation studies of the $\mathrm{Ch} / \mathrm{PEGF}$ blend film at simulated physiological conditions, i.e., pH, enzyme, etc., as well as cell behavior evaluations have not yet been published.

\section{Materials and methods}

\section{Materials}

Low-viscosity Ch ( 80\% DD; 20-200 mPa s, Fluka, Germany) was purified as reported elsewhere (Hashemi Doulabi et al. 2013c). Hen egg white (HEW) lysozyme (46,400 U/ $\mathrm{mg}$ ) and glutaraldehyde were purchased from Sigma-Aldrich (Germany). PEGF $\left(M_{\mathrm{w}}: 19, M_{n}: 16 \mathrm{kDa}\right)$ was synthesized inhouse previously by condensation polymerization of fumaryl chloride with polyethylene glycol (PEG) diol $M_{\mathrm{w}}=3 \mathrm{kDa}$, Merck Chemicals, Dusseldorf, Germany) in the presence of propylene oxide (Hashemi Doulabi et al. 2008). Fumaryl chloride and propylene oxide were obtained from Aldrich, Milwaukee, MN, USA. All other chemicals used were of reagent grade.

\section{Blend film preparation}

Chitosan was blended with PEGF in different blend ratios $(40 / 60,60 / 40,80 / 20)$ and processed into films as previously described (Hashemi Doulabi et al. 2013a). Briefly, filtered mixtures of $\mathrm{Ch}$ and PEGF containing $1 \mathrm{~g} / \mathrm{dL}$ of solid content were dissolved in $1 \% \mathrm{v} / \mathrm{v}$ aqueous acetic acid and poured into petri dishes and left to completely dry at room temperature and then dried in vacuo for $48 \mathrm{~h}$.

\section{Biodegradation assay}

In vitro degradation profile of blend films $(1.5 \mathrm{~cm} \times 1.5 \mathrm{~cm})$ with average thickness of 30-70 $\mu \mathrm{m}$ was followed for a duration of 4 weeks in PBS containing $1.5 \mu \mathrm{g} / \mathrm{mL}$ HEW lysozyme. The test was performed in accordance with the procedure described elsewhere with some modifications ( $\mathrm{Li}$ et al. 2010). Briefly, films with calculated dry weight were neutralized in $1 \mathrm{~N} \mathrm{NaOH}$, washed with deionized water and incubated in the lysozyme solution with gentle mechanical agitation at $37.5^{\circ} \mathrm{C}$. The samples were removed from the medium at predetermined time intervals, i.e., 1, 7, 14 and 28 days and the $\mathrm{pH}$ of the incubation media was also recorded. The samples were washed with deionized water, dehydrated using absolute ethanol and dried to constant weight in an oven $\left(40{ }^{\circ} \mathrm{C}\right)$ and weighted. The weight loss (\%) at different intervals was calculated by Eq. (1) (Tanuma et al. 2010). To separate between enzymatic degradation and dissolution, control samples were incubated for 28 days under the same conditions (PBS, $T=37.5^{\circ} \mathrm{C}$ and $\mathrm{pH}$ 7.4) without the enzyme addition. Media were replaced every 2 days.

Weight loss $(\%)=\frac{W_{0}-W_{t}}{W_{0}} \times 100$,

where $W_{0}$ is the initial weight before degradation test and $W_{t}$ is the dry weight at predetermined time $t$.

\section{In vitro study}

Biocompatibility and cytocompatibility tests were carried out by exposing a cell line of mouse fibroblast (L929) with the films after one, three and five incubation days, in vitro. These assays were accomplished according to the procedures reported by Luna et al. (2011). Cultured mouse fibroblasts (L929, the cell bank of National Institute of Genetic Engineering and Biotechnology, Iran) were harvested with a $0.25 \%$ Trypsin-EDTA solution (Sigma) in a phosphatebuffered saline (PBS; pH 7.4) and re-suspended in the culture medium composed of RPMI-1640 with L-glutamine (Sigma, USA), supplemented with $10 \%$ fetal bovine serum (FBS, Gibco, Germany), 1\% Pen-Strep (100 IU/mL penicillin and $10 \mathrm{mg} / \mathrm{mL}$ streptomycin, Sigma-Aldrich, USA). A cell suspension was prepared with a concentration of approximately $1 \times 10^{6}$ cell $/ \mathrm{mL}$ and seeded onto 12 -well plates in contact with the sterilized films. These plates were incubated for 1,3 and 5 days at $37{ }^{\circ} \mathrm{C}$ in a wet atmosphere containing $5 \% \mathrm{CO}_{2}$. Afterward, the images of cells fixed on the film surfaces were taken by scanning electron microscopy (SEM). To this end, cells were fixed using $2.5 \%$ glutaraldehyde (Sigma-Aldrich, Germany) in a PBS solution and dehydrated using a series of ethanol solutions $(25,30,50$, $70,80,90,100 \% \mathrm{v} / \mathrm{v})$. The samples were dried overnight at room temperature, coated with gold by sputtering and observed by SEM. Cell count and cell spreading measurements were conducted by Image-pro Plus 6 software (Version 6.0.0. 260, Media Cybernetics Inc.). Cell count and cell spreading measurements were conducted using Image-pro Plus 6 software (Version 6.0.0. 260, Media Cybernetics Inc.) (Karkhaneh et al. 2011).

The cell viability was evaluated by MTT 3-(4,5-dimethylthiazol-2-yl)-2,5-diphenyltetrazolium bromide, Merck, Germany) assay by enzymatic conversion of MTT after the time intervals of 1, 3 and 5 days and the results were expressed as a percentage of cell viability. A cell suspension was prepared 
with a concentration of approximately $6.2 \times 10^{5} \mathrm{cell} / \mathrm{mL}$ and seeded onto 96-well plates containing sterilized films. After each interval, $100 \mu \mathrm{L}$ of MTT solution $(0.5 \mathrm{mg} / \mathrm{mL}$ in PBS) was added to each well and incubated for $4 \mathrm{~h}$ at $37{ }^{\circ} \mathrm{C}$ in a humidified atmosphere. The MTT reagent was then removed from the wells and $200 \mu \mathrm{L} 2$-propanol was added to dissolve the formazan crystals. Cell viability has been determined using Absorbance Microplate Reader (BioTek ELx808, USA) at $570 \mathrm{~nm}$ with the reference wavelength of $650 \mathrm{~nm}$.

\section{Statistical analyses}

All experiments were repeated three times with triplicate samples for each group. Analysis of variance (ANOVA) and linear regression were the main statistical tools used for data analysis. The Tukey ( $\alpha=0.05,95 \%$ confidence intervals) was also used to determine the significance of differences observed between specific means (Origin ${ }^{\circledR}, 7.0,2002$, USA).

\section{Results and discussion}

\section{Biodegradation assay}

Chitosan is enzymatically degradable in human serum in the presence of lysozyme by hydrolyzing glycosidic bonds present in the Ch backbone (Nordtveit et al. 1996). In this study, biodegradation behavior was characterized at physiological $\mathrm{pH}$ and enzyme concentration similar to that in human serum. Figure 1 shows an increment in the weight loss of the blend films with increasing the PEGF content in the composition of the films $(p<0.05)$. On day 1 of incubation, the film

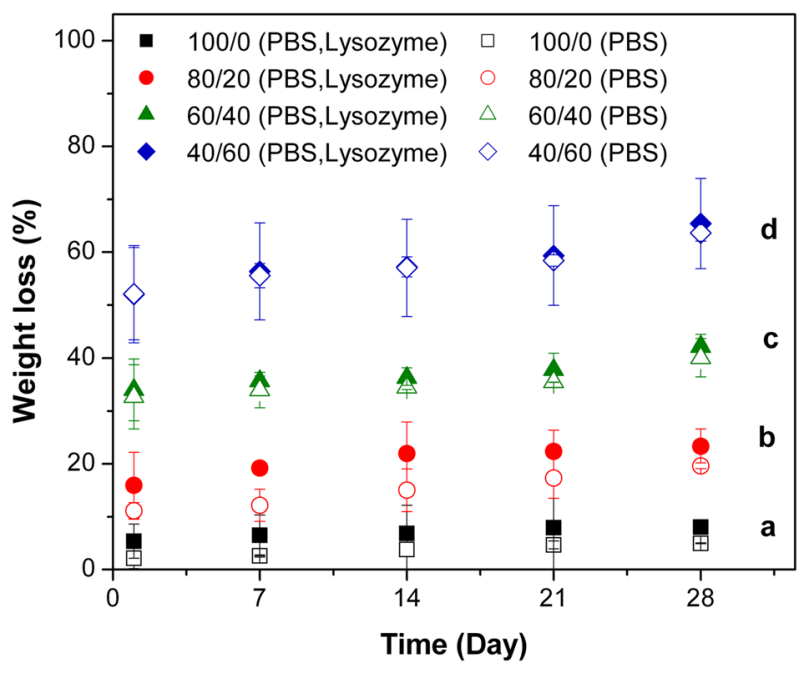

Fig. 1 In vitro degradation behaviors of $\mathrm{Ch}$ and $\mathrm{Ch} / \mathrm{PEGF}$ blend films with different blend ratios: weight loss vs. the time in two types of media-with/without lysozyme with $80 / 20$ in the blend ratio showed the least dissolution among the blends, degradation in media without enzyme (ca. $11 \%$ ) according to weight loss results due to PEGF content in its formulation. Enzymatic degradation and simple dissolution of $\mathrm{Ch} / \mathrm{PEGF}$ blend films with different blend ratios were compared together. As seen in Fig. 1, it seems that the weight loss of the film with $80 / 20$ in blend ratio in the enzyme-supplemented medium was greater than the one in PBS without lysozyme due to the loss of $\mathrm{Ch}$. In contrast to this blend, the effect of lysozyme on degradation rates of the films with 60/40 and 40/60 in blend ratios between two groups, the enzyme-supplemented medium and PBS without lysozyme was not statistically significant $(p>0.05)$. In other words, Ch degradation was not effectively influenced by the enzyme concentration here. It may be attributed to the highly deacetylated $\mathrm{Ch}$ which is less susceptible to lysozyme (Nordtveit et al. 1996; VandeVord et al. 2002). Moreover, as the PEGF content in the blend films increased, the weight loss differences between the two groups were lost due to the prevalent contribution of hydrolytic degradation of PEGF segments; thus the hydrolytic degradation phenomenon could cover the enzymatic degradation outcome. Therefore, the effect of lysozyme was negligible within 28 days and for enzymatic degradation.

When a medium contains $\mathrm{Ch}$, the $\mathrm{pH}$ of the environment could influence the patterns of solubility and enzymatic degradation of $\mathrm{Ch}$. It is worthy to mention that $\mathrm{Ch}$ is soluble in aqueous solution only at $\mathrm{pH}<6.2$, while its degradation rate reaches the maximum value at a $\mathrm{pH}$ of 5.2. To clarify the degradation behavior of the Ch-based polymer, the $\mathrm{pH}$ of incubation media was recorded and analyzed (Fig. 2). Interestingly, on the first day, there was a statistically significant increase in the $\mathrm{pH}$ of all sample media from 7.44 to 7.52

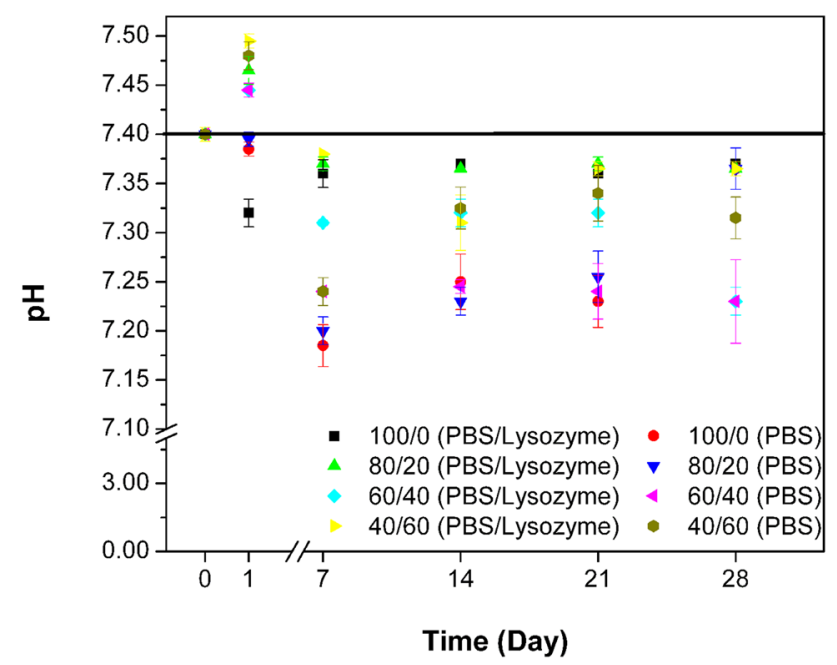

Fig. 2 In vitro degradation behaviors of $\mathrm{Ch}$ and $\mathrm{Ch} / \mathrm{PEGF}$ blend films with different blend ratios: $\mathrm{pH}$ changes vs. the time in two types of media-with/without lysozyme 
First day
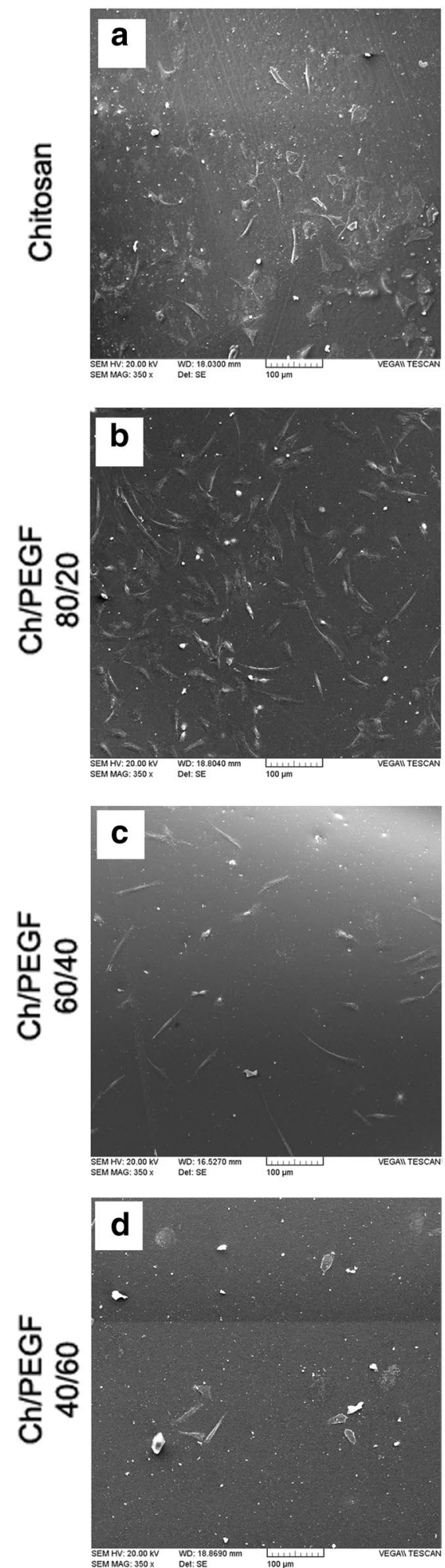

Third day
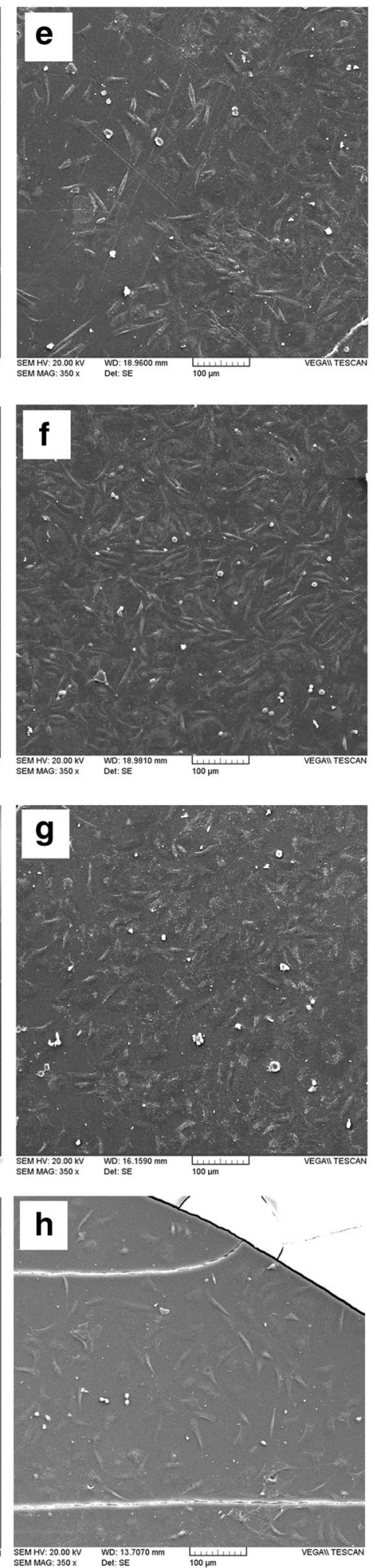

Fifth day
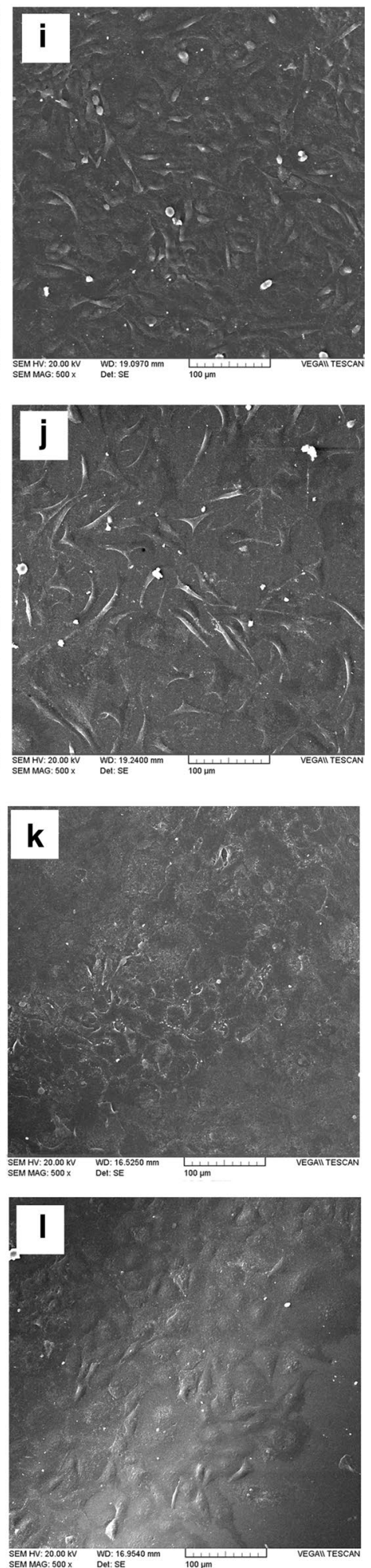

Fig. 3 SEM micrographs of L929 fibroblast cell behaviors in contact with Ch and Ch/PEGF blend films after different incubation intervals as shown on the images $(\mathbf{a}-\mathbf{l})$, scale bar $100 \mu \mathrm{m}$ 


\section{First day}
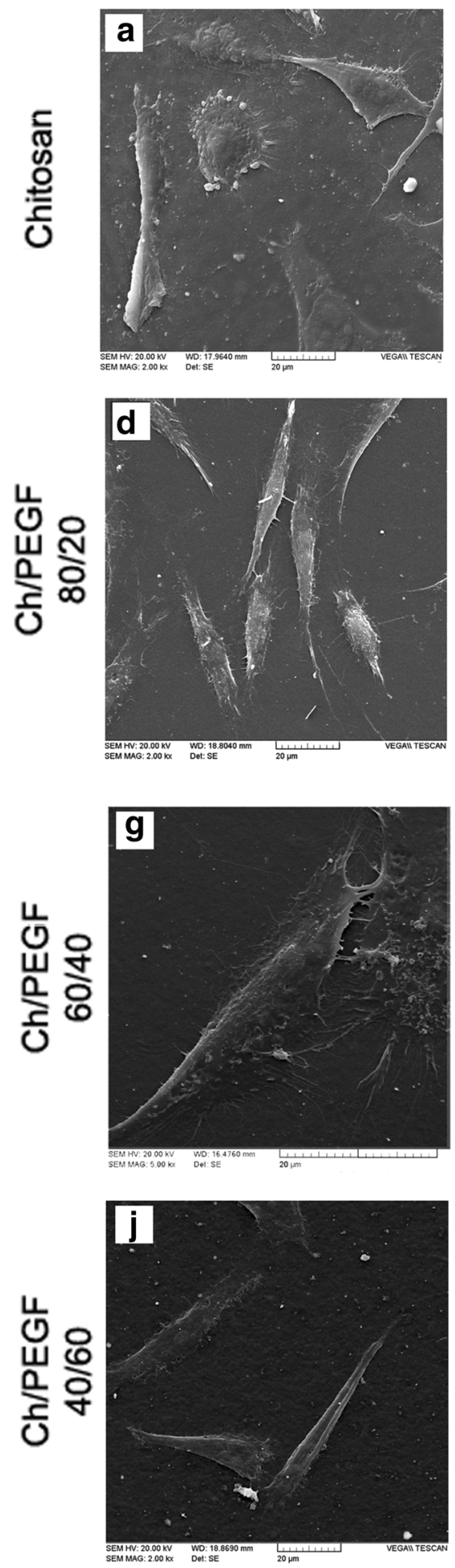

Third day
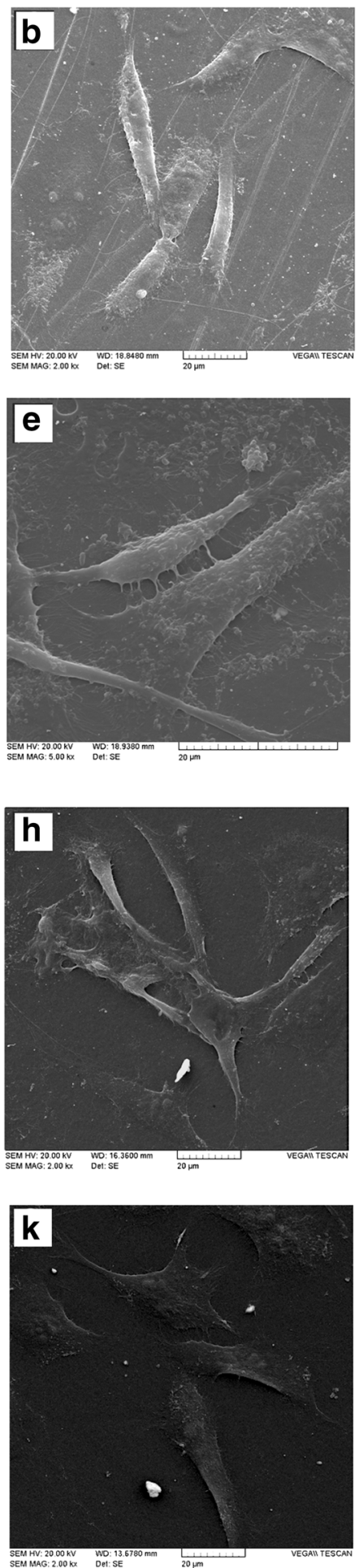

\section{Fifth day}
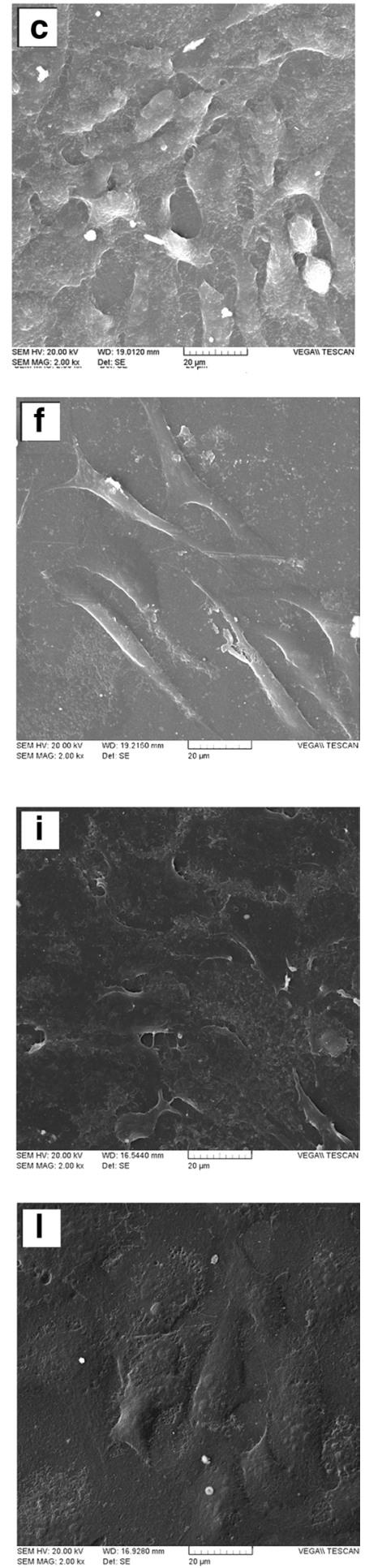

Fig. 4 SEM micrographs of L929 fibroblast cell behaviors in contact with Ch and Ch/PEGF blend films after different incubation intervals as shown in the images (a-l), scale bar $20 \mu \mathrm{m}$ 
$(p<0.05)$. This may be attributed to semi-stable adherence of $\mathrm{NaOH}$, to $\mathrm{Ch}$ through the naturalizing process as reported for the blend of $\mathrm{Ch}$ and PCL which has also reported by Sarasam et al. (2006). Figure 2 shows that the $\mathrm{pH}$ changes in the polymer degradation media due to different film compositions were not significantly different at any measured time point and the $\mathrm{pH}$ was nearly set on an average value of 7.35 throughout the experiment. The free PEG segments presented in the sol fraction also did not influence the $\mathrm{pH}$. Another important point was the blend films with 80/20, 60/40 in Ch/PEGF that keep their integrities and shapes well after 28 days of tests, which means these films can cover the wound area during the healing process. Therefore, they are suitable for application as wound dressings.

\section{Cell morphology}

It has been reported that the properties of the blend surface could influence the cell attachment (Zhang et al. 2002). The cellular behavior in response to a biomaterial is an important factor determining the biocompatibility. When cells contact the biomaterial, cells undergo different morphological changes to stabilize the cell-material interface (Wang et al. 2003). The whole process of adhesion and spreading of cells on the biomaterial surface includes four factors cell attachment, filopodial growth, cytoplasmic webbing, and flattening of the cell mass. Cell adhesion depends on several factors such as surface topography, surface chemistry, surface energy, and hydrophilicity as well as sample chemical composition (Hashemi Doulabi et al. 2013b). In other words, the presence of some effective cell/surface interactions, suitable wettability, and adequate roughness are some examples that could improve cell affinity. Figure $3 \mathrm{a}-1$ shows cell adhesions and morphologies of L929 fibroblasts cultured on the $\mathrm{Ch}$ and its blend films after 1, 3 and 5 days of incubation, indicating that they are alive on the hydrogels and suggesting that our hydrogel is biocompatible in vitro. It can be seen that the cultured cells on the first day show clear morphologies in different stages (Fig. 4a-1). SEM examination showed the morphological type of fibroblasts on the chitosan film was in the first stage of the whole process of adhesion and spreading of cells. Moreover, the cell spreading on the chitosan film was less than the blend ones. It may be attributed to the lower surface energy and the existence of some inter-molecular interactions of chitosan functional groups. However, at the same culturing period, fibroblasts morphologies on Ch/PEGF blend films (80/20 and 60/40 in blend ratios) was in the attachment, filopodial growth, cytoplasmic webbing, flattening of the cell mass stages which is consistent with the situation expected for biocompatible materials.

As illustrated in Fig. 3b-j, the attached cell counts on the film with $80 / 20$ in blend ratio is more than those adhered to the blend films with $60 / 40$ and 40/60 blend composition ratios. It was published that the modified surfaces with PEGbase hydrogels allowed efficient control over cell adhesion. The contact angle of the blend with 80/20 in blend ratio was reported at $59.90^{\circ}$, showing that these materials had good hydrophilicity thereby they were suitable for cell supporting (Hashemi Doulabi et al. 2013b; Solouk et al. 2011). In fact, the simultaneous existence of $\mathrm{Ch}$ and PEGF on the surface could influence surface energy and surface charge; therefore, there are synergistic effects on the cell growth.

The amounts of cell spreading $\left(\mu \mathrm{m}^{2}\right)$ and cell count (cell/ $\mathrm{mm}^{2}$ ) on chitosan film and its blends with PEGF in different blend $\mathrm{Ch} / \mathrm{PEGF}$ ratios after culturing for 1 day are summarized in Table 1. The accurate measurement of cell count and cell spreading was not possible on the third day of incubation. On day 5, the morphology of fibroblasts was in flattened and networking stages; however, the cell count measurement was not also possible due to the forming a single layer of fibroblasts. The cells could attach to the surface of chitosan film and Ch/PEGF blend films. In other words, the addition of the PEGF into chitosan for improving physicochemical and mechanical properties did not impair biological properties of chitosan. These films were biocompatible and provided a suitable substrate for fibroblasts growth. This finding could be confirmed by MTT assay in the next section. Similar to blends based on chitosan and PEG, the results showed that blends of $\mathrm{Ch} / \mathrm{PEGF}$ could improve cell adhesion (Zhang et al. 2002). Adding PEGF up to $40 \%$ (by wt) could support cells; however, PEGF more than $60 \mathrm{wt} \%$ in the blend could decrease surface charge leading to reduced spreading and filopodia. The reason could be associated with the thickness and crystallinity of the films that could be confirmed with our previous finding (Hashemi Doulabi et al. 2013b; Uygun et al. 2010).

Thus, the film of $\mathrm{Ch} / \mathrm{PEGF}$ with $80 / 20$ in the blend ratio could be chosen as the best candidate for wound dressing material, which strongly supports our previous results (Hashemi Doulabi et al. 2013b).

\section{MTT assay}

The MTT assay was accomplished to measure mitochondrial activity and cell viability. It relies on the ability of the viable cells to reduce a water-soluble yellow dye (MTT) to a

Table 1 The degree of fibroblasts cell spreading and the number of spreading cells on the blend films with various blend ratios and chitosan film after 1 day of incubation

\begin{tabular}{lllll}
\hline Film composition & Chitosan & \multicolumn{3}{l}{ Ch/PEGF blend ratio } \\
\cline { 3 - 5 } & & $80 / 20$ & $60 / 40$ & $40 / 60$ \\
\hline Cell area $\left(\mathrm{m}^{2}\right)$ & $464 \pm 127$ & $500 \pm 71$ & $496 \pm 87$ & $466 \pm 107$ \\
Cell count $\left(\mathrm{cell} / \mathrm{mm}^{2}\right)$ & $552 \pm 110$ & $530 \pm 168$ & $240 \pm 130$ & $65 \pm 3$ \\
\hline
\end{tabular}



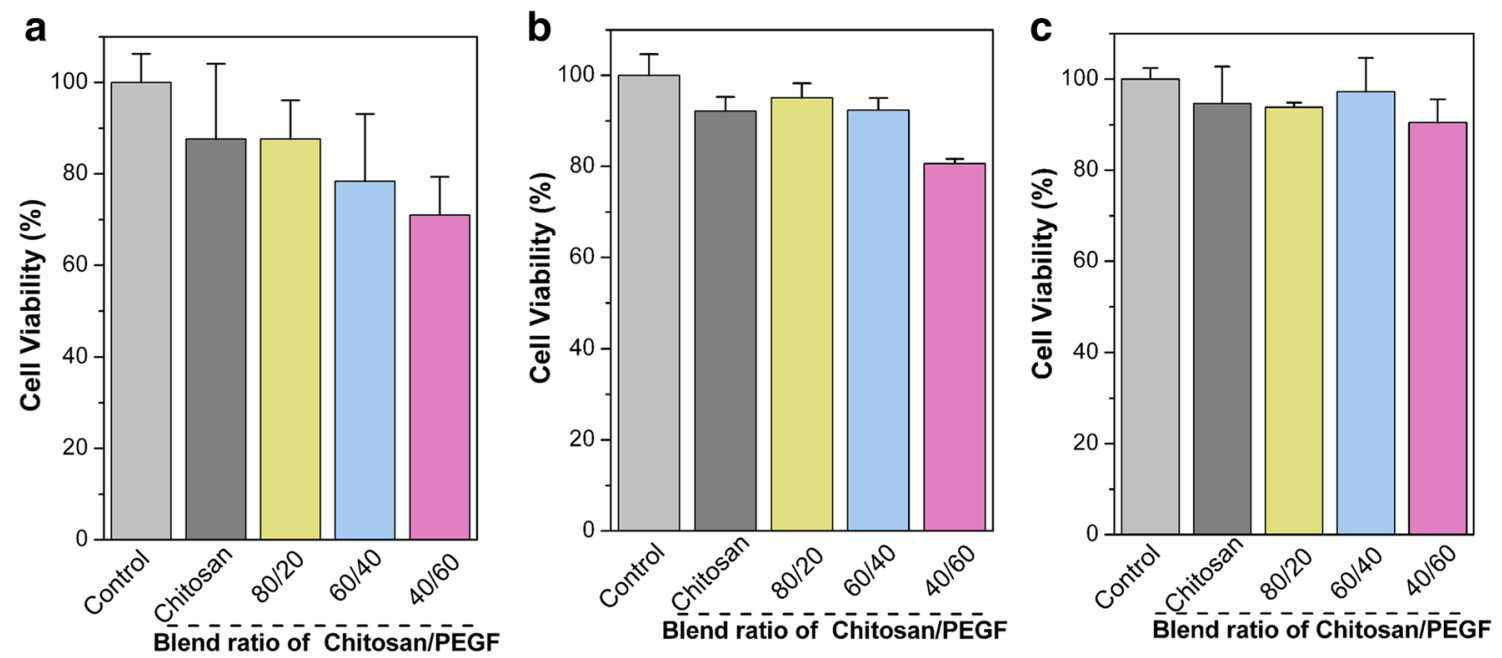

Fig. 5 Cell viability results of $\mathrm{Ch}$ and $\mathrm{Ch} / \mathrm{PEGF}$ blend films after 1 (a), 3 (b) and 5 (c) incubation days; tissue-culture polystyrene plate used as a control, $n=5$

water-insoluble purple formazan product. Figure 5a-c shows the cell viabilities of the $\mathrm{Ch} / \mathrm{PEGF}$ blend films in contact with L929 fibroblasts after 1, 3 and 5 days of incubation, indicating these are non-toxic, biocompatible and cytocompatible (cell viability $>75 \%$ ). According to Fig. 5 , the blend ratio could significantly influence the cell viability at the 1st, 3rd and 5th days of incubation; the higher the Ch contents, the higher cell viability, for which SEM images confirmed MTT results. This may be due to the presence of amino groups in the Ch backbone. MTT results also showed that the blending process did not impair the cell viabilities of the blend films in comparison to the Ch film in the 1st, 3rd and 5 th days of incubation $(p>0.05)$. As a final point, the cell behavior analyses highlight a good cell viability, proliferation, and distribution, pointing out a good biocompatibility profile of the Ch/PEGF films in contact with L929 fibroblast cells. In other words, $\mathrm{Ch} / \mathrm{PEGF}$ with $80 / 20$ in the blend ratio could promote cell attachment; therefore, chitosan could improve biological properties of PEGF.

\section{Conclusions}

In this study, $\mathrm{Ch} / \mathrm{PEGF}$ blend films were prepared with different blend ratios. In vitro degradation results revealed that any decrement in Ch/PEGF blend ratio resulted in a corresponding increase in their degradation rate due to higher PEGF water solubility. The $\mathrm{pH}$ evaluations made in the polymer degradation media showed the presence of that enzyme with a concentration similar to the human serum that was negligible. Cell behaviors toward all the formulations showed acceptable high biocompatibility and nontoxicity properties with fibroblast L929 cells under in vitro testing conditions. The film of Ch/PEGF with $80 / 20$ of blend ratio was chosen as the optimum support for wound dressing applications due to biodegradation and biocompatibility properties as well as keeping their integrity during 28 days after incubation. We believe these films with such properties can be widely applied to biomedical applications such as a wound dressing material.

Acknowledgements The authors would like to express their sincere gratitude to Iran National Science Foundation (no. 89001749) for supporting this research.

\section{Compliance with ethical standards}

Conflict of interest The authors declare no conflict of interest.

Open Access This article is distributed under the terms of the Creative Commons Attribution 4.0 International License (http://creativeco mmons.org/licenses/by/4.0/), which permits unrestricted use, distribution, and reproduction in any medium, provided you give appropriate credit to the original author(s) and the source, provide a link to the Creative Commons license, and indicate if changes were made.

\section{References}

Ahmed S, Ikram S (2016) Chitosan based scaffolds and their applications in wound healing. Achiev Life Sci 10:27-37

Cao Y, Wang B (2009) Biodegradation of silk biomaterials. Int J Mol Sci 10:1514-1524

Hashemi Doulabi A, Mirzadeh H, Imani M, Sharifi S, Atai M, Mehdipour-Ataei S (2008) Synthesis and preparation of biodegradable and visible light crosslinkable unsaturated fumarate-based networks for biomedical applications. Polym Adv Technol 19:1199-1208 
Hashemi Doulabi A, Mirzadeh H, Imani M (2013a) Interaction and miscibility study of fumarate-based oligomer macromers with chitosan. Mater Chem Phys 139:515-524

Hashemi Doulabi A, Mirzadeh H, Imani M, Samadi N (2013b) Chitosan/polyethylene glycol fumarate blend film: physical and antibacterial properties. Carbohydr Polym 92:48-56

Hashemi Doulabi A, Mirzadeh H, Imani M (2013c) Miscibility study of chitosan/polyethylene glycol fumarate blends in dilute solutions. J Appl Polym Sci 127:3514-3521

Hashemi Doulabi A, Mirzadeh H, Samadi N, Bagheri-Khoulenjani S, Atai M, Imani M (2015) Potential application of a visible lightinduced photocured hydrogel film as a wound dressing material. J Polym 2015:1-10

Karkhaneh A, Mirzadeh H, Ghaffariyeh A, Ebrahimi A, Honarpisheh N, Hosseinzadeh M, Heidari MH (2011) Novel materials to enhance corneal epithelial cell migration on keratoprosthesis. $\mathrm{Br}$ J Ophthalmol 95:405-409

Kean T, Thanou M (2010) Biodegradation, biodistribution and toxicity of chitosan. Adv Drug Delivery Rev 62:3-11

Li X et al (2010) Biodegradable MPEG- $g$-Chitosan and methoxy poly(ethylene glycol)- $b$-poly ( $\varepsilon$-caprolactone) composite films: part 1. Preparation and characterization. Carbohydr Polym 79:429-436

Luna SM, Silva SS, Gomes ME, Mano JF, Reis RL (2011) Cell adhesion and proliferation onto chitosan-based membranes treated by plasma surface modification. J Biomater Appl 26:101-116

Mir M, Ali MN, Barakullah A, Gulzar A, Arshad M, Fatima S, Asad M (2018) Synthetic polymeric biomaterials for wound healing: a review. Prog Biomater 7:1-21

Muxika A, Etxabide A, Uranga J, Guerrero P, de la Caba K (2017) Chitosan as a bioactive polymer: processing, properties and applications. Int J Biol Macromol 105:1358-1368

Muzzarelli RAA (2009) Chitins and chitosans for the repair of wounded skin, nerve, cartilage and bone. Carbohydr Polym 76:167-182

Nordtveit RJ, Varum KM, Smidsrod O (1996) Degradation of partially $\mathrm{N}$-acetylated chitosans with hen egg white and human lysozyme. Carbohydr Polym 29:163-167
Sarasam AR, Krishnaswamy RK, Madihally SV (2006) Blending chitosan with polycaprolactone: effects on physicochemical and antibacterial properties. Biomacromolecules 7:1131-1138

Solouk A, Cousins BG, Mirzadeh H, Solati-Hashtjin M, Najarian S, Seifalian AM (2011) Surface modification of POSS-nanocomposite biomaterials using reactive oxygen plasma treatment for cardiovascular surgical implant applications. Biotechnol Appl Biochem 58:147-161

Tanuma H, Saito T, Nishikawa K, Dong T, Yazawa K, Inoue Y (2010) Preparation and characterization of PEG-cross-linked chitosan hydrogel films with controllable swelling and enzymatic degradation behavior. Carbohydr Polym 80:260-265

Usman A, Zia KM, Zuber M, Tabasum S, Rehman S, Zia F (2016) Chitin and chitosan based polyurethanes: a review of recent advances and prospective biomedical applications. Int J Biol Macromol 86:630-645

Uygun BE, Bou-Akl T, Albanna M, Matthew HWT (2010) Membrane thickness is an important variable in membrane scaffolds: influence of chitosan membrane structure on the behavior of cells. Acta Biomater 6:2126-2131

VandeVord PJ, Matthew HWT, DeSilva SP, Mayton L, Wu B, Wooley PH (2002) Evaluation of the biocompatibility of a chitosan scaffold in mice. J Biomed Mater Res 59:585-590

Wang J-H, Wei C-W, Liu H-C, Young T-H (2003) Behavior of MG-63 cells on nylon/chitosan-blended membranes. J Biomed Mater Res Part A 64:606-615

Zhang M, Li XH, Gong YD, Zhao NM, Zhang XF (2002) Properties and biocompatibility of chitosan films modified by blending with PEG. Biomaterials 23:2641-2648

Publisher's Note Springer Nature remains neutral with regard to jurisdictional claims in published maps and institutional affiliations. 